\title{
A Bioactivity-Based Method for Screening, Identification of Lipase Inhibitors, and Clarifying the Effects of Processing Time on Lipase Inhibitory Activity of Polygonum Multiflorum
}

\author{
Yan-xu Chang, ${ }^{1,2}$ Ai-hua Ge,, ${ }^{1,2}$ Yan Jiang, ${ }^{1,2}$ John Teye Azietaku, \\ Jin $\mathrm{Li}^{1,2}$ and Xiu-mei Gao ${ }^{1,2}$ \\ ${ }^{1}$ Tianjin State Key Laboratory of Modern Chinese Medicine, Tianjin University of Traditional Chinese Medicine, Tianjin 300193, China \\ ${ }^{2}$ Tianjin Key Laboratory of Phytochemistry and Pharmaceutical Analysis, Tianjin University of Traditional Chinese Medicine, \\ Tianjin 300193, China \\ Correspondence should be addressed to Yan-xu Chang; tcmcyx@126.com and Xiu-mei Gao; gaoxiumei@tjutcm.edu.cn
}

Received 24 September 2015; Revised 4 January 2016; Accepted 5 January 2016

Academic Editor: Youn C. Kim

Copyright (C) 2016 Yan-xu Chang et al. This is an open access article distributed under the Creative Commons Attribution License, which permits unrestricted use, distribution, and reproduction in any medium, provided the original work is properly cited.

\begin{abstract}
Traditional Chinese medicine (TCM) has been used for the treatment of many complex diseases. However, the bioactive components are always undefined. In this study, a bioactivity-based method was developed and validated to screen lipase inhibitors and evaluate the effects of processing on the lipase inhibitory activity of TCM by ultrahigh performance liquid chromatography coupled with quadrupole-time-of-flight mass spectrometry and fraction collector (UHPLC/Q-TOF-MS-FC). The results showed that both Polygonum multiflorum and processed P. multiflorum extracts had inhibitory effect against lipase with $\mathrm{IC}_{50}$ values of $38.84 \mu \mathrm{g} / \mathrm{mL}$ and $190.6 \mu \mathrm{g} / \mathrm{mL}$, respectively. Stilbenes, phenolic acid, flavonoids, and anthraquinones were considered to be the potential lipase inhibitors. Eleven potential lipase inhibitors were simultaneously determined by UHPLC. Principal component analysis (PCA) was employed in exploring the effects of processing time on lipase inhibitory activity of $P$. multiflorum. Compared with conventional methods, a bioactivity-based method could quantitatively analyze lipase inhibitory activity of individual constituent and provide the total lipase inhibitory activity of the samples. The results demonstrated that the activity integrated UHPLC/Q-TOF-MS-FC method was an effective and powerful tool for screening and identifying lipase inhibitors from traditional Chinese medicines.
\end{abstract}

\section{Introduction}

Nowadays, obesity presents as a main health problem in the world, which is often associated with pathological disorders $[1,2]$. Obesity is caused by excessive energy intake over low energy expenditure, leading to the accumulation of fat in the body. The fat contained in food is the excess energy source. In order to reduce fat accumulation in the body, the digestion and absorption of the fat after food intake should be prevented [3]. At present, lipase has been selected as a therapeutic target for the prevention of fat digestion. There are some synthetic pancreatic lipase inhibitors such as orlistat, used widely as effective antiobesity drugs [3,4]. However, long term usage of these drugs has various side effects such as liver toxicity, abdominal distention, and borborygmus [5].
From this perspective, it is necessary to screen green and safe lipase inhibitors from natural products.

For this purpose, many plants including traditional Chinese medicines (TCMs) have been used for the treatment of obesity [6-9]. Polygonum multiflorum (Heshouwu in Chinese), obtained from the root of P. multiflorum Thunb., is an example of a TCM used over centuries for the treatment of various kinds of diseases in China [10]. The main components in P. multiflorum are stilbenes, phenolic acids, flavonoids, and anthraquinones [11-13]. Phenolic compounds, such as gallic acid and catechin, have antioxidant activity in vivo in previous reports $[14,15]$. Moreover, anthraquinones have antiinflammatory, hemostatic, laxative, and antibacterial activities [16]. Specifically, stilbenes are known for their effect in 
treating neurodegenerative diseases, such as Alzheimer's disease and Parkinson's disease [17-19]. They are the active components contributing to the pharmacological effects of $P$. $m u l$ tiflorum. There are reports on the lipid-lowering activity of P. multiflorum for the treatment of hyperlipidemia in animal and cell experiments [20-22]. However, the lipid regulation mechanisms were still not clearly elucidated. Therefore, lipase was selected as a key enzyme to screen lipase inhibitors for elucidating the lipid regulation mechanisms of $P$. multiflorum.

It is a great challenge for separating, screening, and identifying lipase inhibitors from TCMs due to the complexity and variability of components. Besides, traditional screening method of isolating, purifying, and evaluating lipase inhibitors using animal and cell models is time-consuming and labor-intensive and this makes it difficult screening lipase inhibitors in TCMs directly [23]. The lipase inhibitors may be lost during the process of isolation and purification. Thus, it is very necessary to establish a rapid and simple method in obtaining relatively pure compounds from bioassays. It could be applied directly to screen lipase inhibitors from TCMs. In order to overcome the disadvantages flogged with the use of conventional methods, HPLC coupled with bioassays was used to screen bioactive components [24,25]. With the development of modern techniques, UHPLC-Q-TOF/MS has been widely used in the screening of components from TCMs not only for its high peak capacity, high sensitivity, and resolution but also for the exact mass determination by the Q-TOF/MS $[26,27]$. Furthermore, the fraction collector (FC) is a useful tool for the rapid sample preparation to test the activity of chromatographic fractions.

In this study, bioactivity-based UHPLC-Q-TOF/MS-FC method was applied to screen the lipase inhibitors and evaluate the effects of processing time on inhibitory lipase activity of $P$. multiflorum. In the approach, UHPLC coupled with FC was used for the rapid sample preparation of the bioassays. UHPLC-Q-TOF/MS was employed to provide chemical information on the lipase inhibitors from TCMs. Finally, the screened and identified lipase inhibitors were simultaneously determined by UHPLC-PDA to evaluate the effects of processing on the quality of $P$. multiflorum. The method could reflect the bioactivity of the whole extract and individual components, structure-activity relationships, concentrationeffect relationships, and the concentration of individual compounds. This novel technique may help to discover lipase inhibitors rapidly and efficiently and help evaluate the effects of processing on the quality of TCMs and its benefits in drug research and development.

\section{Experimental}

2.1. Plant Materials. P. multiflorum was purchased from Anguo TCM market (Hebei, China) and authenticated by Professor Lin Ma (Tianjin University of Traditional Chinese Medicine). P. multiflorum was processed by black soybean decoction according to the Chinese Pharmacopoeia, into the processed $P$. multiflorum. The procedure was as follows: $P$. multiflorum was mixed with black bean extract for $24 \mathrm{~h}(10 \mathrm{~g}$ black bean extracted with $200 \mathrm{~mL}$ water twice), it was finally steamed for $36 \mathrm{~h}$, and then the processed P. multiflorum was obtained. $5.0 \mathrm{~kg}$ processed $P$. multiflorum and $P$. multiflorum powder were fluxed with $5 \mathrm{~L} 95 \%$ ethanol and refluxed with $8 \mathrm{~L} 60 \%$ ethanol for $2 \mathrm{~h}$, respectively. Then, the extraction was combined, condensed, and lyophilized. The extraction yield was $17.2 \%$ for $P$. multiflorum and $9.45 \%$ for the processed $P$. multiflorum. Finally, the plant materials were obtained.

2.2. Chemicals and Reagents. Acetonitrile, purchased from Merck (Darmstadt, Germany), and methanol purchased from (Tianjin Concord Science Co. Ltd., Tianjin, China) were of HPLC grade. Formic acid of chromatographic grade was purchased from Tedia Company Inc. (Tedia, Fairfield, $\mathrm{OH}$, USA). Deionized water was purified with a Milli-Q Academic ultrapure water system (Millipore, Milford, MA, USA). Reference standards of gallic acid, catechin, epicatechin, polydatin, 2,3,5,4' -tetrahydroxystilbene-2-O- $\beta$-D-glucoside, resveratrol, emodin-8-O-glucoside, physcion-8-O-glucoside, rhein, emodin, and physcion (purity $>98 \%$ ) were purchased from Chengdu Must Biotechnology Co., Ltd. (Chengdu, China). Lipase (type II, L3126) was purchased from Solar Bio Science Co. Ltd. (Beijing, China). Orlistat (purity > 98\%) was obtained from Sigma-Aldrich (St. Louis, Missouri, USA). Other reagents were of analytical grade and obtained commercially.

\subsection{Sample Preparations}

2.3.1. Preparation of the P. multiflorum Extract. The extracts of processed $P$. multiflorum and P. multiflorum ( $0.05 \mathrm{~g}$ ) were weighed accurately and extracted with $10 \mathrm{~mL} 70 \%(\mathrm{v} / \mathrm{v})$ methanol ultrasonically for $40 \mathrm{~min}$. After centrifugation at $14,000 \mathrm{rpm}$ for $10 \mathrm{~min}$, the supernatants were filtered through $0.22 \mu \mathrm{m}$ filter. Then, the solutions were injected into the UHPLC system for the fraction collection and the quality control of $P$. multiflorum or diluted to obtain the suitable concentrations for bioassays. The contents of gallic acid, catechin, epicatechin, polydatin, 2,3,5,4' -tetrahydroxystilbene-2-O- $\beta$ $\mathrm{D}$-glucoside, resveratrol, emodin-8-O-glucoside, physcion8-O-glucoside, rhein, emodin, and physcion in P. multiflorum extract were $0.146 \mathrm{mg} / \mathrm{g}, 0.035 \mathrm{mg} / \mathrm{g}, 0.140 \mathrm{mg} / \mathrm{g}, 0.138 \mathrm{mg} / \mathrm{g}$, $57.497 \mathrm{mg} / \mathrm{g}, 0.192 \mathrm{mg} / \mathrm{g}, 7.885 \mathrm{mg} / \mathrm{g}, 0.584 \mathrm{mg} / \mathrm{g}, 0.052 \mathrm{mg} / \mathrm{g}$, $0.444 \mathrm{mg} / \mathrm{g}$, and $0.656 \mathrm{mg} / \mathrm{g}$, respectively. Those in processed P. multiflorum extract were $0.528 \mathrm{mg} / \mathrm{g}, 0.001 \mathrm{mg} / \mathrm{g}$, $0.03 \mathrm{mg} / \mathrm{g} 7,0.076 \mathrm{mg} / \mathrm{g}, 29.824 \mathrm{mg} / \mathrm{g}, 3.352 \mathrm{mg} / \mathrm{g}, 0.215 \mathrm{mg} / \mathrm{g}$, $0.054 \mathrm{mg} / \mathrm{g}, 1.354 \mathrm{mg} / \mathrm{g}$, and $2.074 \mathrm{mg} / \mathrm{g}$, respectively.

2.3.2. Preparation of the Fractions. When the $P$. multiflorum extract was injected into the UHPLC system, the fraction collector (BSZ-100, Shanghai QingpuHuxi Instrument, Shanghai, China) was used for the fraction collection by setting the time interval at $20 \mathrm{~s}$. Then, the fractions were collected and evaporated to dryness by nitrogen gas. The residues were reconstituted and diluted for bioassays.

2.3.3. Preparation of Substrate and Enzyme Solutions. 4Methylumbelliferyl oleate $(4.406 \mathrm{mg}$ ) was accurately weighed and dissolved by Tris- $\mathrm{HCl}$ solution ( $\mathrm{pH}$ 8.0, $1.3 \mathrm{mM} \mathrm{NaCl}$, and $1.3 \mathrm{mM} \mathrm{CaCl}_{2}$ ) with the final concentration of $0.1 \mathrm{mM} .100 \mathrm{mg}$ 
lipase was dissolved with deionized water and the insoluble substances were removed by centrifugation at 14,000 rpm for $10 \mathrm{~min}$. Finally, the concentration of enzyme solution was $1.0 \mathrm{mg} / \mathrm{mL}$.

2.3.4. Preparation of Standard Solutions. Gallic acid, catechin, epicatechin, polydatin, 2,3,5,4' -tetrahydroxystilbene-2-O- $\beta$ $\mathrm{D}$-glucoside, resveratrol, emodin-8-O-glucoside, physcion8-O-glucoside, rhein, emodin, and physcion with the concentration of $1.0 \mathrm{mg} / \mathrm{mL}$ were prepared in methanol for quality control. Rhein, emodin, and physcion were dissolved in DMSO (Dimethyl Sulfoxide) with suitable concentrations. The reference standards solution was diluted serially with $10 \%$ methanol for the bioassays. The concentrations of DMSO in a series of samples at different concentrations were less than $0.1 \%(\mathrm{v} / \mathrm{v})$. Orlistat was used as the positive control of lipase, respectively. It was prepared with $10 \%$ methanol and diluted to a series of different concentrations.

2.4. UHPLC Analysis. The separation of P. multiflorum extract was operated on a Waters Acquity UHPLC System (Waters Co., Milford, MA). UHPLC system was equipped with PDA detector of 190-400 nm. An Acquity UHPLC BEH C18 $(1.7 \mu \mathrm{m}, 2.1 \times 50 \mathrm{~mm})$ column was employed for the separations. The mobile phases were made up of $0.1 \%(\mathrm{v} / \mathrm{v})$ formic acid aqueous solution (A) and acetonitrile (B) with a gradient elution of $0-1 \mathrm{~min}, 5 \%-5 \% \mathrm{~B}$; $1-7 \mathrm{~min}, 5 \%-20 \% \mathrm{~B}$; 7-10 min, 20\%-35\% B; $10-15 \mathrm{~min}, 35 \%-65 \% \mathrm{~B} ; 15-18 \mathrm{~min}, 65 \%-80 \%$ B; and $18-18.1 \mathrm{~min}, 80 \%-5 \%$ B. Reequilibration time after gradient elution was $5 \mathrm{~min}$. The flow rate was $0.3 \mathrm{~mL} \mathrm{~min}{ }^{-1}$. The column temperature was set at $30^{\circ} \mathrm{C}$. The injection volume was $1 \mu \mathrm{L}$.

2.5. UHPLC-Q-TOF-MS Analysis. The components in $P$. multiflorum extract were identified by an Agilent Q-TOFMS system. Aglient 6520 Q-TOF mass spectrometer (Agilent Corporation, Santa Clara, CA, USA) coupled with the Agilent 1290 HPLC via an ESI interface was used to obtain chemical information. The mobile phases, flow rate, column temperature, and injection volume were the same as in the UHPLC analysis. The detection wavelengths were set at 254 for emodin and physcion and at $280 \mathrm{~nm}$ for other components. The gradient elution was set as follows: $0-4 \mathrm{~min}, 3 \%-12 \% \mathrm{~B}$; 4-8 min, $12 \%-15 \%$ B; 8-13 min, $15 \%-25 \%$ B; $13-16$ min, $25 \%-$ $50 \% \mathrm{~B}$; and $16-20 \mathrm{~min}, 50 \%-80 \% \mathrm{~B}$. Reequilibration time after gradient elution was $5 \mathrm{~min}$. The ESI-MS spectra were obtained in both positive and negative ion modes to provide complete information for the compounds identification. The Q-TOF-MS analysis conditions were set as follows: capillary voltage, $4500 \mathrm{~V}$; fragmentor voltage, $175 \mathrm{~V}$; skimmer voltage, $65 \mathrm{~V}$; drying gas temperature, $350^{\circ} \mathrm{C}$; drying gas $\left(\mathrm{N}_{2}\right)$ flow rate, $10 \mathrm{~L} / \mathrm{min}$; nebulizer gas pressure, $35 \mathrm{psig}$; and octopole $\mathrm{RF}, 750 \mathrm{~V}$. The mass range was $m / z 100-1000$. The ions [M$\mathrm{H}]^{-}$were selected as precursor ions and subjected to target$\mathrm{MS} / \mathrm{MS}$ analysis.

2.6. Method Validation. The method validation including linearity, limits of detection (LOD), limits of quantification
(LOQ), repeatability, precision, stability, and recovery was performed on the basis of US Pharmacopeia recommendations and guidelines.

2.6.1. Linearity, Repeatability, LODs, and LOQs. The calibration curves were constructed with the diluted concentrations of the reference compounds by plotting the peak areas $(y)$ versus the corresponding concentration $(x, \mu \mathrm{g} / \mathrm{mL})$. The repeatability was evaluated by six independent sample solutions and expressed as the relative standard deviation (RSD). The stocks solution of the reference compounds was diluted to a certain concentration at the signal-to-noise $(S / N)$ ratio of 3 and 10, respectively. Six independent sample solutions were evaluated for the repeatability test.

2.6.2. Precision, Stability, and Recovery. The intraday and interday variability were used for the evaluation of the precision. Intraday and interday precision were assessed by the standard solutions of three different concentrations (low, medium, and high concentration) within one day and over three consecutive days, respectively. The variability was expressed as RSD. The stability experiment was determined for the standard solutions at three different concentrations at the time interval of $0,2,4,6,8,12$, and $24 \mathrm{~h}$ at room temperature. The recovery was determined by spiking three different concentrations $(80 \%, 100 \%$, and $120 \%)$ of the eleven compounds into certain amount $(0.05 \mathrm{~g})$ of the P. multiflorum and then the mixed solutions were extracted and analyzed by the above method. Finally, the recovery was calculated by the formula: recovery $(\%)=$ (found amount - original amount $) /$ spiked amount $\times 100 \%$.

2.6.3. Repeatability and Recovery of Fraction Collections. The P. multiflorum extract was injected into the UHPLC system and then collected by the FC. Six batches (six times of the collection were used as a batch) were collected to evaluate the repeatability of the fraction collection method. Eleven known components were selected as markers to determine the yield of the collected fractions. The same peak was divided into several fractions, which were combined and condensed to dryness by nitrogen gas. The recovery of the fraction was assessed by the ratio of the peak content in the reconstituted fraction and in the P. multiflorum extract, which was employed to evaluate the loss in the process of fraction collection.

2.6.4. Sample Analysis. The P. multiflorum extract and processed $P$. multiflorum extract (with different processing times) were analyzed by the developed method. The concentrations of the eleven components were determined.

2.6.5. Assay for Lipase Inhibitory Activity. The assay of lipase was performed according to previous method with slight modifications [28]. $25 \mu \mathrm{L}$ test samples and $25 \mu \mathrm{L}$ lipase solution were mixed together. Then, $50 \mu \mathrm{L}$ 4-methylumbelliferyl oleate was added to the mixture. After incubating at $25^{\circ} \mathrm{C}$ for $20 \mathrm{~min}, 100 \mu \mathrm{L}$ sodium citrate $(0.1 \mathrm{M}, \mathrm{pH} 4.2)$ was added 
TABLE 1: UHPLC data for the calibration curves, LODs, LOQs, and repeatability $(n=6)$.

\begin{tabular}{|c|c|c|c|c|c|c|}
\hline Compounds & Regressive equation & $\begin{array}{c}\text { Linear range } \\
(\mu \mathrm{g} / \mathrm{mL})\end{array}$ & $R^{2}$ & $\begin{array}{c}\text { LOD } \\
(\mu \mathrm{g} / \mathrm{mL})\end{array}$ & $\begin{array}{c}\text { LOQ } \\
(\mu \mathrm{g} / \mathrm{mL})\end{array}$ & $\begin{array}{c}\text { Repeatability } \\
\text { RSD (\%) }\end{array}$ \\
\hline Gallic acid & $Y=5719 x+446.94$ & $0.46 \sim 100$ & 0.9997 & 0.15 & 0.46 & 2.14 \\
\hline Catechin & $Y=507.37 x+341.84$ & $5.56 \sim 100$ & 0.9994 & 1.85 & 5.56 & 1.59 \\
\hline Epicatechin & $Y=625.05 x+370.25$ & $2.78 \sim 100$ & 0.9977 & 0.93 & 2.78 & 3.97 \\
\hline Polydatin & $Y=1279.9 x-13.406$ & $1.67 \sim 100$ & 0.9975 & 0.56 & 1.67 & 2.35 \\
\hline 2,3,5,4'-Tetrahydroxystilbene-2-O- $\beta$-D-glucoside & $Y=1271.8 x+1703.5$ & $2.29 \sim 1000$ & 0.9998 & 0.71 & 2.29 & 1.10 \\
\hline resveratrol & $Y=3466.9 x-263.63$ & $0.56 \sim 100$ & 0.9999 & 0.19 & 0.56 & 1.90 \\
\hline Emodin-8-O-glucoside & $Y=1518.4 x+174.91$ & $1.11 \sim 100$ & 0.9998 & 0.37 & 1.11 & 1.31 \\
\hline Physcion-8-O-glucoside & $Y=3563 x+1665.9$ & $0.33 \sim 100$ & 0.9955 & 0.11 & 0.33 & 1.69 \\
\hline Rhein & $Y=7705 x-1401$ & $0.22 \sim 100$ & 0.9996 & 0.07 & 0.22 & 1.70 \\
\hline Emodin & $Y=11056 x-743.8$ & $0.19 \sim 100$ & 0.9998 & 0.06 & 0.19 & 0.77 \\
\hline Physcion & $Y=2238.3 x-601.47$ & $0.93 \sim 100$ & 0.9996 & 0.31 & 0.93 & 1.92 \\
\hline
\end{tabular}

to stop the reaction. Finally, the amount of 4-methylumbelliferone released by lipase was measured by microplate reader at an excitation wavelength of $355 \mathrm{~nm}$ and an emission wavelength of $460 \mathrm{~nm}$. The inhibitory activity was calculated by the formula: inhibition $(\%)=\left[1-\left(A_{\text {sample }} / A_{\text {control }}\right)\right] \times 100$, where $A_{\text {sample }}$ and $A_{\text {control }}$ were absorbance of the test sample and the control, respectively. Orlistat was used as the positive control.

2.7. Statistical Analysis. In the bioassay experiments, all the analysis was carried out in triplicate. All values were expressed in the form of mean \pm standard deviation $(\mathrm{SD}) ; \mathrm{IC}_{50}$ values were determined by Graph Pad Prism 5 software.

\section{Results and Discussion}

\subsection{Method Validation}

3.1.1. Linearity, LODs, and LOQs. The information of linearity, LODs, and LOQs was listed in Table 1. All compounds had a good linear relationship within the linear range with $R^{2}>$ 0.9955. The LODs and LOQs of the compounds were in the range of 0.06 to $1.85 \mu \mathrm{g} / \mathrm{mL}$ and 0.22 to $5.56 \mu \mathrm{g} / \mathrm{mL}$, respectively.

3.1.2. Precision, Stability, and Recovery. As shown in Table 2, all the RSD values of intraday and interday precision were less than $5 \%$ and $4.91 \%$, respectively. The intraday and interday accuracies were in the range of $94.2 \%-106 \%$ and $93.7 \%-$ $107 \%$. The results indicated that the method was precise for the quantitative analysis and fraction collection of the $P$. multiflorum extract. The RSDs of the stability of the analytes were less than $4.98 \%$ and the accuracy was in the range from $93.7 \%$ to $106 \%$, demonstrating that the sample solutions were stable within $24 \mathrm{~h}$ at room temperature. The RSD values of the recoveries at three different concentrations were less than $4.49 \%$ and the recoveries were in the range of $95.3 \%$ to $105 \%$ (Table 3), which illustrated that the extraction method was of high accuracy.
3.1.3. Recovery of Fraction Collections. The results of the repeatability of enriched fractions were no more than $3.97 \%$ (Table 1), demonstrating that the fraction collection method was reproducible for the rapid sample preparation. The recoveries of the 11 fractions were higher than $71.4 \%$, illustrating that the loss in the enriching process was acceptable and the process was reproducible (data was not given).

3.2. Lipase Inhibitory Activity of P. multiflorum Extract. The lipase inhibitory activity of $P$. multiflorum and processed $P$. multiflorum extracts at the concentration of $4-5000 \mu \mathrm{g} / \mathrm{mL}$ was investigated. The results showed that both $P$. multiflorum and processed $P$. multiflorum extracts have the inhibitory effect against lipase. $\mathrm{IC}_{50}$ values of $P$. multiflorum and processed $P$. multiflorum extracts were $38.84 \mu \mathrm{g} / \mathrm{mL}$ and $190.6 \mu \mathrm{g} / \mathrm{mL}$, respectively. These results indicated that activity of $P$. multiflorum was better than processed P. multiflorum. The contents of 11 typical constituents were determined by UPLC-PDA. It was found that the contents of catechin, epicatechin, polydatin, 2,3,5,4'-tetrahydroxystilbene-2-O- $\beta$-Dglucoside, resveratrol, physcion-8-O-glucoside, and emodin8-O-glucoside in P. multiflorum were higher than those in processed $P$. multiflorum. The contents of gallic acid, rhein, emodin, and physcion in P. multiflorum were lower than those in processed $P$. multiflorum. It was concluded that $P$. multiflorum extract showing better activity than processed $P$. multiflorum is related to contents of some lipase inhibitors. Thus, it was necessary to screen potential lipase inhibitors and P. multiflorum extract was selected for the bioactive fraction collection by the UHPLC-FC.

3.3. Lipase Inhibitory Activity. The extract was injected in UHPLC for the separation of the components and all fractions were collected for the bioassays. The lipase inhibitory effect was expressed as inhibition ratio (\%), which could be calculated by the above mentioned formula. The time interval of fraction collector was set at $20 \mathrm{~s}$ according to the resolution and peak shape in the chromatogram. Thus, the relative purity of the fractions was guaranteed for the bioassays. The fractions from the same peak were combined. From Figure 1, 
TABLE 2: Intraday and interday precision and stability of the 11 compounds $(n=6)$.

\begin{tabular}{|c|c|c|c|c|c|c|c|}
\hline \multirow{2}{*}{ Compounds } & \multirow{2}{*}{ Concentration $(\mu \mathrm{g} / \mathrm{mL})$} & \multicolumn{2}{|c|}{ Intraday } & \multicolumn{2}{|c|}{ Interday } & \multicolumn{2}{|c|}{ Stability } \\
\hline & & RSD (\%) & Accuracy (\%) & RSD (\%) & Accuracy (\%) & RSD (\%) & Accuracy (\%) \\
\hline \multirow{3}{*}{ Gallic acid } & 1 & 4.31 & 96.6 & 1.35 & 97.6 & 4.77 & 106 \\
\hline & 10 & 2.46 & 102 & 0.82 & 107 & 3.96 & 99.3 \\
\hline & 100 & 2.57 & 97.2 & 0.75 & 99.3 & 3.49 & 97.3 \\
\hline \multirow{3}{*}{ Catechin } & 1 & 3.35 & 96.7 & 2.65 & 95 & 4.69 & 100 \\
\hline & 10 & 1.98 & 100 & 1.94 & 101 & 4.98 & 95 \\
\hline & 100 & 2.17 & 98.6 & 2.05 & 95.2 & 4.96 & 95.2 \\
\hline \multirow{3}{*}{ Epicatechin } & 1 & 1.85 & 95.2 & 1.44 & 94.7 & 2.26 & 96.7 \\
\hline & 10 & 4.09 & 103 & 0.08 & 104 & 3.88 & 95.2 \\
\hline & 100 & 3.79 & 94.7 & 0.15 & 94.2 & 4.23 & 103 \\
\hline \multirow{3}{*}{ Polydatin } & 1 & 0.90 & 98.2 & 2.17 & 95.3 & 4.70 & 98.2 \\
\hline & 10 & 3.02 & 106 & 2.80 & 106 & 3.83 & 95 \\
\hline & 100 & 3.12 & 93.8 & 2.75 & 98.2 & 3.96 & 106 \\
\hline \multirow{3}{*}{$\begin{array}{l}2,3,5,4^{\prime}- \\
\text { Tetrahydroxystilbene- } \\
2-O-\beta \text {-D-glucoside }\end{array}$} & 1 & 4.84 & 95 & 1.79 & 97.3 & 3.25 & 93.7 \\
\hline & 10 & 3.50 & 102 & 0.45 & 100 & 4.87 & 96.4 \\
\hline & 100 & 3.21 & 96.6 & 1.88 & 96.7 & 4.64 & 99.3 \\
\hline \multirow{3}{*}{ Resveratrol } & 1 & 4.32 & 102 & 2.15 & 102 & 3.94 & 97.1 \\
\hline & 10 & 3.28 & 97.3 & 4.91 & 96.1 & 4.79 & 97.1 \\
\hline & 100 & 3.29 & 99.3 & 0.81 & 93.7 & 2.91 & 99.5 \\
\hline \multirow{3}{*}{$\begin{array}{l}\text { Emodin-8-O- } \\
\text { glucoside }\end{array}$} & 1 & 2.81 & 101 & 1.80 & 103 & 4.16 & 96.1 \\
\hline & 10 & 3.51 & 96.7 & 1.40 & 96.4 & 3.45 & 106 \\
\hline & 100 & 3.76 & 95 & 0.98 & 96.4 & 3.24 & 93.7 \\
\hline \multirow{3}{*}{$\begin{array}{l}\text { Physcion-8-O- } \\
\text { glucoside }\end{array}$} & 1 & 5.00 & 99.8 & 2.12 & 97.1 & 2.76 & 96.4 \\
\hline & 10 & 4.50 & 96.2 & 1.50 & 95.8 & 4.78 & 99.3 \\
\hline & 100 & 4.68 & 95.2 & 1.45 & 95 & 4.97 & 97.1 \\
\hline \multirow{3}{*}{ Rhein } & 1 & 4.43 & 96.9 & 2.06 & 102 & 2.80 & 95 \\
\hline & 10 & 4.20 & 95.8 & 2.80 & 93.7 & 3.86 & 102 \\
\hline & 100 & 4.67 & 94.7 & 2.79 & 103 & 2.76 & 96.1 \\
\hline \multirow{3}{*}{ Emodin } & 1 & 4.69 & 104 & 2.76 & 96.4 & 4.91 & 96.3 \\
\hline & 10 & 4.46 & 95 & 4.25 & 97.1 & 2.77 & 96.4 \\
\hline & 100 & 4.28 & 94.2 & 3.57 & 95.8 & 3.04 & 97.3 \\
\hline \multirow{3}{*}{ Physcion } & 1 & 3.75 & 106 & 3.01 & 95 & 4.34 & 99.5 \\
\hline & 10 & 4.95 & 96.4 & 2.23 & 102 & 3.77 & 97.2 \\
\hline & 100 & 4.90 & 97.3 & 2.23 & 103 & 3.27 & 95.6 \\
\hline
\end{tabular}

we could observe that the lipase inhibitory activity of the fractions samples that were enriched for 40 and 60 times showed a nonlinear dose-dependent relationship. That is, with the enriched times increasing, the bioactivity of some fractions increased while some did not. When the P. multiflorum extract was enriched for 60 times, the lipase inhibitory activity of some fractions was higher than $50 \%$. As can be seen from Figure 1, the fractions of peaks 5, 6, 7, 8, 9, 10, and 11 showed strong inhibition of lipase, while the peaks 1,2 , 3 , and 4 showed relatively weak inhibitory effect of lipase. These fractions containing 20 bioactive components were screened directly and might be considered as the antilipase active components in P. multiflorum extract. As a result, the established method could be used to screen potential lipase inhibitory TCMs and bioactive components.

3.4. Identification of the Bioactive Components. The identification of the components in P. multiflorum extract was carried out by UHPLC-Q-TOF-MS. The 70\% methanol extract of P. multiflorum was employed to obtain the total ion chromatogram (TIC) of MS study and MS/MS study of the fragment ion. As can be seen from Table 4, 11 compounds were 
TABLE 3: The recovery of eleven bioactive compounds $(n=3)$.

\begin{tabular}{|c|c|c|c|c|c|}
\hline Analyte & Original $(\mu \mathrm{g})$ & Spiked $(\mu \mathrm{g})$ & Found $(\mu \mathrm{g})$ & Average recovery (\%) & RSD (\%) \\
\hline \multirow{3}{*}{ Gallic acid } & \multirow{3}{*}{3.52} & 2.82 & 6.21 & 95.3 & 0.88 \\
\hline & & 3.52 & 6.91 & 96.2 & 1.44 \\
\hline & & 4.23 & 7.90 & 104 & 1.85 \\
\hline \multirow{3}{*}{ Catechin } & \multirow{3}{*}{2.39} & 1.91 & 4.31 & 100 & 4.49 \\
\hline & & 2.39 & 4.85 & 103 & 0.61 \\
\hline & & 2.87 & 5.23 & 98.7 & 2.70 \\
\hline \multirow{3}{*}{ Epicatechin } & \multirow{3}{*}{9.08} & 7.26 & 16.4 & 101 & 0.73 \\
\hline & & 9.08 & 18.1 & 99.3 & 0.09 \\
\hline & & 10.9 & 20.3 & 103 & 0.33 \\
\hline \multirow{3}{*}{ Polydatin } & \multirow{3}{*}{15.8} & 12.7 & 28.3 & 98.6 & 3.93 \\
\hline & & 15.8 & 32.5 & 105 & 0.34 \\
\hline & & 19.0 & 35.4 & 103 & 0.83 \\
\hline \multirow{3}{*}{$2,3,5,4^{\prime}$-Tetrahydroxystilbene-2-O- $\beta$-D-glucoside } & \multirow{3}{*}{519} & 415 & 949 & 104 & 1.64 \\
\hline & & 519 & 1030 & 98.4 & 0.37 \\
\hline & & 623 & 1168 & 104 & 0.64 \\
\hline \multirow{3}{*}{ Resveratrol } & \multirow{3}{*}{9.14} & 7.31 & 16.7 & 103 & 1.06 \\
\hline & & 9.14 & 18.3 & 100 & 0.95 \\
\hline & & 11.0 & 19.9 & 98.4 & 1.59 \\
\hline \multirow{3}{*}{ Emodin-8-O-glucoside } & \multirow{3}{*}{21.3} & 17.1 & 39.1 & 104 & 1.86 \\
\hline & & 21.3 & 41.9 & 96.4 & 0.81 \\
\hline & & 25.6 & 47.1 & 101 & 2.87 \\
\hline \multirow{3}{*}{ Physcion-8-O-glucoside } & \multirow{3}{*}{7.86} & 6.29 & 14.4 & 104 & 1.57 \\
\hline & & 7.86 & 16.1 & 105 & 0.67 \\
\hline & & 9.43 & 17.6 & 104 & 0.82 \\
\hline \multirow{3}{*}{ Rhein } & \multirow{3}{*}{3.53} & 2.82 & 6.42 & 103 & 1.65 \\
\hline & & 3.53 & 6.95 & 97.2 & 1.29 \\
\hline & & 4.23 & 7.70 & 98.5 & 1.45 \\
\hline \multirow{3}{*}{ Emodin } & \multirow{3}{*}{5.79} & 4.63 & 10.5 & 102 & 0.77 \\
\hline & & 5.79 & 11.7 & 102 & 0.98 \\
\hline & & 6.95 & 13.0 & 104 & 1.06 \\
\hline \multirow{3}{*}{ Physcion } & \multirow{3}{*}{3.39} & 2.71 & 6.21 & 104 & 1.47 \\
\hline & & 3.39 & 6.64 & 95.9 & 1.07 \\
\hline & & 4.07 & 7.46 & 99.9 & 0.39 \\
\hline
\end{tabular}

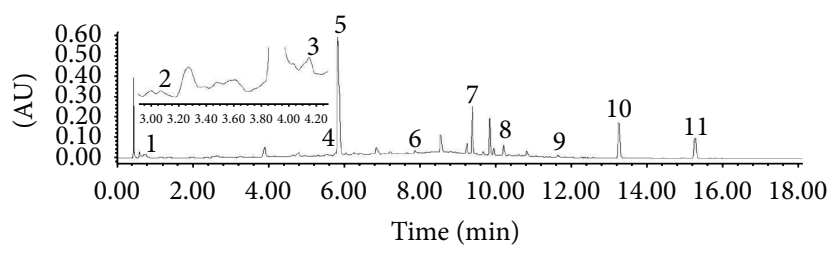

(a)

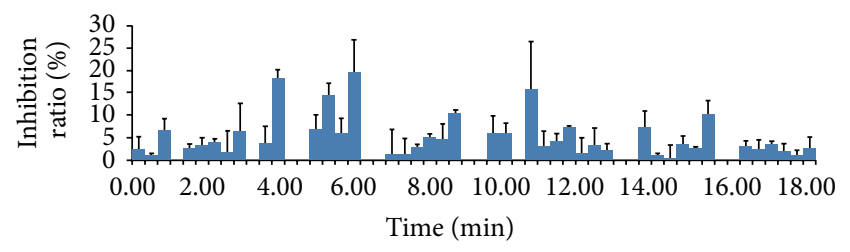

(b)

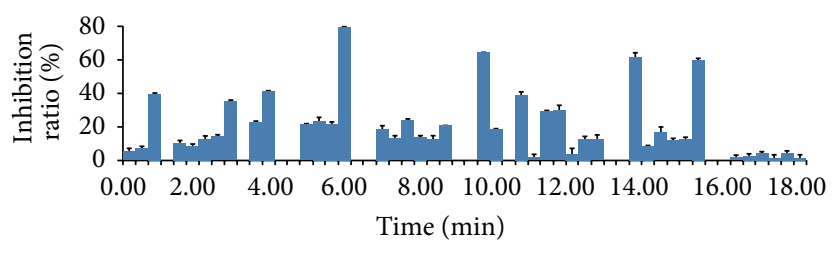

(c)

FIGURE 1: The chromatogram (a) and lipase inhibitory effect of enriched fractions for 40 times (b) and 60 times (c). 
TABLE 4: UHPLC/Q-TOF-MS identification of lipase inhibitors and $\mathrm{IC}_{50}$ values.

\begin{tabular}{|c|c|c|c|c|c|c|c|}
\hline Number & Rt (min) & MS & MS/MS & $\mathrm{ppm}$ & Formula & Compound & $\mathrm{IC}_{50}(\mu \mathrm{g} / \mathrm{mL})$ \\
\hline 1 & 1.409 & 169.0141 & & 4.6 & $\mathrm{C}_{7} \mathrm{H}_{6} \mathrm{O}_{5}$ & Gallic acid & - \\
\hline 2 & 3.725 & 289.0724 & $\begin{array}{c}215.0714,173.0535 \\
149.0206,125.0215 \\
109.0283\end{array}$ & 2.2 & $\mathrm{C}_{15} \mathrm{H}_{14} \mathrm{O}_{6}$ & Catechin & - \\
\hline 3 & 4.48 & 289.0724 & $\begin{array}{c}276.4677,205.0499 \\
163.0368,131.0053 \\
109.0317\end{array}$ & 2.2 & $\mathrm{C}_{15} \mathrm{H}_{14} \mathrm{O}_{6}$ & Epicatechin & - \\
\hline 4 & 6.484 & 389.1168 & 227.1165 & 3.89 & $\mathrm{C}_{20} \mathrm{H}_{22} \mathrm{O}_{8}$ & $\begin{array}{l}\text { Polydatin } \\
\end{array}$ & 1318 \\
\hline 5 & 6.766 & 405.1184 & $243.0656,137.0237$ & 0.95 & $\mathrm{C}_{20} \mathrm{H}_{22} \mathrm{O}_{9}$ & 2,3,5,4'-Tetrahydroxystilbene-2-O- $\beta$-D-glucoside & 350.5 \\
\hline 6 & 9.203 & 227.2002 & $\begin{array}{c}202.0698,176.0559 \\
99.9223,91.0179 \\
73.5614\end{array}$ & 3.35 & $\mathrm{C}_{14} \mathrm{H}_{12} \mathrm{O}_{3}$ & Resveratrol & 564.3 \\
\hline 7 & 10.597 & 431.1386 & $269.0448,225.0540$ & 0.86 & $\mathrm{C}_{21} \mathrm{H}_{20} \mathrm{O}_{10}$ & Emodin-8-O-glucoside & 296.0 \\
\hline 8 & 11.836 & 445.0595 & $283.0595,240.0415$ & 0.76 & $\mathrm{C}_{22} \mathrm{H}_{22} \mathrm{O}_{10}$ & Physcion-8-O-glucoside & 421.5 \\
\hline 9 & 12.127 & 283.0606 & 240.0409 & 3.76 & $\mathrm{C}_{15} \mathrm{H}_{8} \mathrm{O}_{6}$ & Rhein & 231.0 \\
\hline 10 & 17.188 & 269.0460 & $\begin{array}{c}241.0491,225.0549 \\
210.0312,197.0598\end{array}$ & 3.89 & $\mathrm{C}_{15} \mathrm{H}_{10} \mathrm{O}_{5}$ & Emodin & 349.7 \\
\hline 11 & 18.786 & 283.0610 & $240.0419,116.9278$ & 0.88 & $\mathrm{C}_{16} \mathrm{H}_{12} \mathrm{O}_{5}$ & Physcion & 812.8 \\
\hline
\end{tabular}

identified or characterized tentatively according to previous reports. Among the identified compounds, there were 1 phenolic acid, 2 flavonoids, 3 stilbenes, and 5 anthraquinones.

Peaks 1, 2, and 3 were unambiguously identified as gallic acid, catechin, and epicatechin, respectively, by comparing mass spectrometric behavior and retention time with the reference compounds. Peak 4 produced $[\mathrm{M}-\mathrm{H}]^{-}$at $\mathrm{m} / z 389.1168$ with the molecular formula $\mathrm{C}_{20} \mathrm{H}_{21} \mathrm{O}_{8}$. A loss of $\mathrm{C}_{6} \mathrm{H}_{10} \mathrm{O}_{5}$ in MS/MS study was confirmed to be a hexose neutral loss. Peak 4 was tentatively identified as polydatin by comparing the MS data with literature [29]. The MS and MS/MS spectra of peak 5 gave diagnostic ions at $m / z 405.1$ and 243.1, of which the elemental compositions were $\mathrm{C}_{20} \mathrm{H}_{21} \mathrm{O}_{10}$ and $\mathrm{C}_{14} \mathrm{H}_{11} \mathrm{O}_{4}$. Further fragmentation produced characteristic ions at $\mathrm{m} / z$ 215 and 137. Peak 5 was tentatively characterized as $2,3,5,4^{\prime}-$ tetrahydroxystilbene-2-O- $\beta$-D-glucoside [30]. The negative MS spectra of peak 6 exhibited a parent ion $[\mathrm{M}-\mathrm{H}]^{-}$at $m / z$ 227.2, while a fragment ion at $\mathrm{m} / z$ 185.2, 143.1, and 119.2 was observed in MS/MS spectra. Based on the previous literature, peak 6 was identified as resveratrol [31]. Emodin8-O-glucoside (peak 7) and physcion-8-O-glucoside (peak 8) were identified certainly by comparing the characteristic mass spectra with the reference standards. The negative MS spectra of peak 9 showed a parent ion $[\mathrm{M}-\mathrm{H}]^{-}$at $m / z 283.1$ and fragment ion at $m / z 239.0$ was observed in MS/MS spectra, which was tentatively characterized as rhein according to the previous report [32]. The characteristic fragment ions of 283.1, 269.0, and 240.0, the elemental composition, and characteristic fragmentation behaviors could be employed to identify the anthraquinone derivatives. Two components, emodin (peak 10) and physcion (peak 11), were unambiguously identified by comparing mass spectra and retention times with their reference compounds.
As a result, peaks of 1-11 were identified as gallic acid, catechin, epicatechin, polydatin, 2,3,5,4'-tetrahydroxystilbene-2-O- $\beta$-D-glucoside, resveratrol, emodin-8-O-glucoside, physcion-8-O-glucoside, rhein, emodin, and physcion, respectively. As a more sensitive and reliable method, the integrated MS identification and activity screening method could be used in screening bioactive components and identification of components from natural products. The chemical information of $P$. multiflorum extract also provided helpful information of the activity study and could be used in the compound identification of other similar TCMs.

3.5. The Contribution of Lipase Inhibitory Activity. The inhibitory effect of positive control orlistat against lipase was determined and $\mathrm{IC}_{50}$ value was calculated by the software Graph Pad Prism 5. The $\mathrm{IC}_{50}$ value of orlistat was $0.167 \mu \mathrm{g} / \mathrm{mL}$. The $\mathrm{IC}_{50}$ of orlistat was defined as a potency unit. The potency of other concentrations of orlistat was calculated by the potency unit. The potency calibration curve was constructed by plotting the potency $(y)$ against the corresponding inhibition ratio $(x)$. The calibration curve of orlistat was $y=0.0033 x^{3}-$ $0.5271 x^{2}+28.111 x-497.27\left(R^{2}=0.9956\right)$. Then, the potency of the enriched fractions was determined by the curve mentioned above. Therefore, the relative percentages of inhibition of lipase of all identified fractions expressed potency unit of orlistat equivalent antilipase capacity according to standard potency curves. The contribution of individual fractions was calculated by the formula: contribution $(\%)=$ potency of individual fraction/the total lipase inhibitory $\times 100 \%$. The results showed that the $2,3,5,4^{\prime}$-tetrahydroxystilbene-2-O- $\beta$ $\mathrm{D}$-glucoside played the most important role in the lipase inhibitory effect contributing more than $70 \%$ while phenolic 


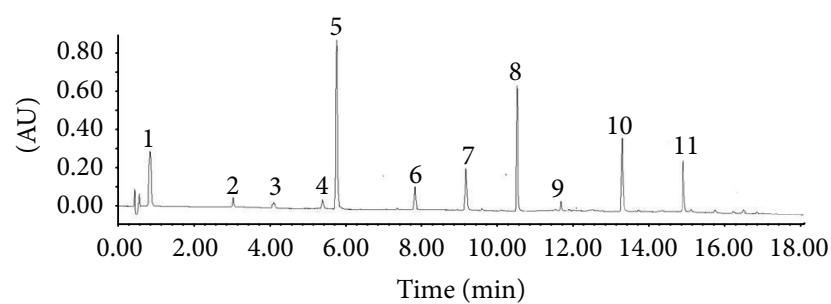

(a)

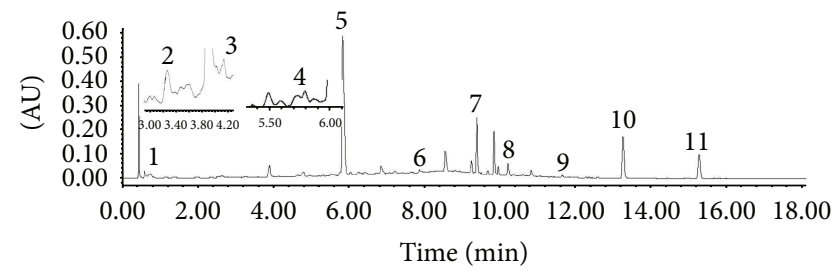

(b)

FIGURE 2: The UHPLC chromatogram of the quantitative analysis of 11 components. (a) The mixed standard solutions of 11 components. (b) The P. multiflorum extract $\left(1=\right.$ gallic acid, $2=$ catechin, $3=$ epicatechin, $4=$ polydatin, $5=2,3,5,4^{\prime}$-tetrahydroxystilbene- 2 - $\mathrm{O}-\beta$ - $\mathrm{D}$-glucoside, $6=$ resveratrol, $7=$ emodin-8-O-glucoside, $8=$ physcion- 8 -O-glucoside, $9=$ rhein, $10=$ emodin, and $11=$ physcion).

acid, flavonoids, and other two stilbenes made relatively little contribution to the whole activity. Anthraquinones like emodin-8-O-glucoside, emodin, and physcion made moderate contribution to the total activity contributing less than $10 \%$ of the total activity. The possible reasons might be that the $2,3,5,4^{\prime}$-tetrahydroxystilbene-2-O- $\beta$-D-glucoside does have strong inhibitory effect against lipase and the content of it was the highest among all the components. As a result, $2,3,5,4^{\prime}$-tetrahydroxystilbene-2-O- $\beta$-D-glucoside and anthraquinones were the main components exhibiting lipase inhibitory effect. The results were consistent with that of the activity of the fractions.

3.6. Confirmation of the Bioactivity of the Bioactive Components. In order to validate the results obtained from the established method, the bioassays of the reference standards of the bioactive components (purity > 98\%) from the P. multiflorum extract were carried out at the same time. Eight different diluted concentrations of the bioactive components of the lipase inhibitory effect were assessed. The effective concentration at which lipase was inhibited by $50 \%$ was defined as $\mathrm{IC}_{50}$ values of the components against lipase. The inhibitory effect of the compounds was expressed as inhibition ratio (\%). The results were listed in Table 4. Except gallic acid, catechin, and epicatechin, the lipase inhibition ratio of the compounds was above $50 \%$ at the concentration of $1.0 \mathrm{mg} / \mathrm{mL}$, which was consistent with the inhibitory activity of the bioactive fractions. The $\mathrm{IC}_{50}$ values of the bioactive components with the lipase inhibition ratio more than 50\% were calculated. The lipase inhibitory effects of rhein, emodin-8-Oglucoside, emodin, 2,3,5, $4^{\prime}$-tetrahydroxystilbene-2-O- $\beta$-Dglucoside, and physcion-8-O-glucoside were stronger with their $\mathrm{IC}_{50}$ values being 231.0, 296.0, 349.7, 350.5, and $421.5 \mu \mathrm{g} / \mathrm{mL}$, respectively. Those of polydatin, resveratrol, and physcion were $1318,564.3$, and $812.8 \mu \mathrm{g} / \mathrm{mL}$, of which their inhibitory effect against lipase was relatively weaker. As a result, stilbenes and anthraquinones were screened to have the potential inhibitory effect against lipase from the $P$. multiflorum extract. The results might be of significant value to clinical drug use.

3.7. The Effects of Processing on Quality of P. multiflorum Extract. 11 components were screened and identified by the developed UHPLC-Q-TOF/MS-FC method (Figure 2). In

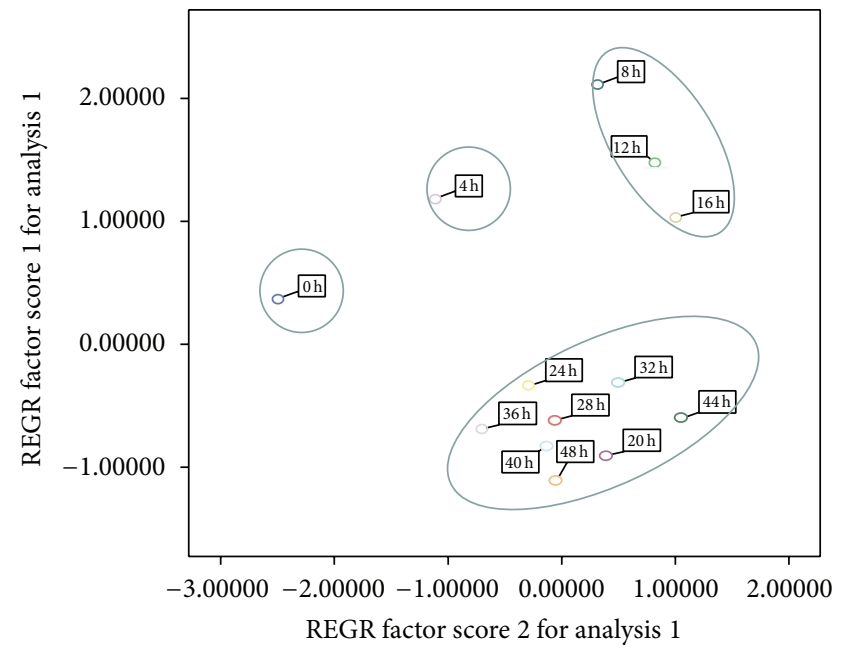

FIGURE 3: The score plot of $P$. multiflorum with different processing times.

order to clarify the effect of processing on lipase activity, the different processing times on contents of lipase inhibitors were investigated. The contents of 11 compounds were determined simultaneously for the comprehensive quality control of the P. multiflorum extract. The chromatogram of quantitative analysis is illustrated in Figure 3. After the P. multiflorum was processed, the contents of phenolic acid (gallic acid) and flavonoids (catechin and epicatechin) were enhanced, while the contents of stilbenes (polydatin, 2,3,5, $4^{\prime}$ tetrahydroxystilbene-2-O- $\beta$-D-glucoside, and resveratrol) were reduced. Among the anthraquinones, the contents of physcion, rhein, and emodin were enhanced and those of physcion-8-O-glucoside and emodin-8-O-glucoside were depressed. The P. multiflorum extracts of different processing times were also calculated. The results were shown in Table 5. As can be seen from Table 5, the contents of gallic acid, catechin, and epicatechin had no regular changes with different processing times, while the contents of polydatin, 2,3,5,4' -tetrahydroxystilbene- $2-\mathrm{O}-\beta$-D-glucoside, and resveratrol were decreased. The reason was that polydatin, 2,3,5,4' -tetrahydroxystilbene-2-O- $\beta$-D-glucoside, and resveratrol lose glycosides in the processing procedure. The contents of physcion, rhein, and emodin improved with the 
TABLE 5: Contents of 11 compounds in samples of different processed times $(\mathrm{mg} / \mathrm{g}, n=3)$.

\begin{tabular}{|c|c|c|c|c|c|c|c|c|c|c|c|c|c|}
\hline \multirow{2}{*}{ Compounds } & \multicolumn{13}{|c|}{ Contents (mg/g) } \\
\hline & $0 \mathrm{~h}$ & $4 \mathrm{~h}$ & $8 \mathrm{~h}$ & $12 \mathrm{~h}$ & $16 \mathrm{~h}$ & $20 \mathrm{~h}$ & $24 \mathrm{~h}$ & $28 \mathrm{~h}$ & $32 \mathrm{~h}$ & $36 \mathrm{~h}$ & $40 \mathrm{~h}$ & $44 \mathrm{~h}$ & $48 \mathrm{~h}$ \\
\hline Gallic acid & 0.35 & 0.84 & 1.02 & 0.58 & 1.09 & 1.10 & 1.45 & 1.25 & 1.84 & 2.45 & 1.69 & 1.97 & 1.73 \\
\hline Catechin & 0.25 & 1.57 & 0.94 & 0.23 & 0.13 & 0.00 & 0.30 & 0.00 & 0.25 & 0.59 & 0.75 & 0.21 & 0.72 \\
\hline Epicatechin & 1.05 & 0.94 & 1.36 & 0.42 & 0.53 & 0.26 & 0.45 & 0.45 & 0.60 & 0.60 & 0.43 & 0.39 & 0.48 \\
\hline Polydatin & 1.57 & 1.34 & 1.04 & 0.87 & 0.77 & 0.73 & 0.68 & 0.59 & 0.55 & 0.48 & 0.42 & 0.33 & 0.32 \\
\hline $2,3,5,4^{\prime}$-Tetrahydroxystilbene-2-O- $\beta$-D-glucoside & 52.1 & 44.3 & 43.8 & 42.4 & 34.4 & 32.6 & 32.2 & 27.6 & 25.8 & 24.9 & 21.3 & 13.6 & 12.1 \\
\hline Resveratrol & 0.99 & 0.97 & 0.77 & 0.73 & 0.69 & 0.29 & 0.61 & 0.39 & 0.54 & 0.80 & 0.52 & 0.39 & 0.37 \\
\hline Emodin-8-O-glucoside & 5.40 & 4.05 & 2.62 & 2.38 & 2.16 & 2.22 & 1.96 & 1.63 & 1.41 & 1.31 & 0.98 & 0.79 & 0.68 \\
\hline Physcion-8-O-glucoside & 1.79 & 1.47 & 1.18 & 1.12 & 1.09 & 1.12 & 1.09 & 0.80 & 0.67 & 0.52 & 0.30 & 0.04 & 0.03 \\
\hline Rhein & 0.00 & 0.07 & 0.09 & 0.10 & 0.17 & 0.30 & 0.39 & 0.47 & 0.10 & 0.30 & 0.09 & 0.17 & 0.06 \\
\hline Emodin & 0.58 & 1.46 & 2.08 & 3.08 & 3.20 & 3.39 & 3.64 & 3.76 & 2.31 & 3.11 & 1.47 & 2.62 & 1.34 \\
\hline Physcion & 0.34 & 1.11 & 1.49 & 1.69 & 2.36 & 2.99 & 3.62 & 3.71 & 1.12 & 1.45 & 0.63 & 1.11 & 0.56 \\
\hline
\end{tabular}

processing times until $32 \mathrm{~h}$, after which the contents showed no regular changes. The concentrations of physcion-8-Oglucoside and emodin-8-O-glucoside presented a completely opposite tendency. The reason was that physcion-8-Oglucoside and emodin-8-O-glucoside were physcion and emodin derivative, respectively. Before $32 \mathrm{~h}$, physcion-8-Oglucoside and emodin-8-O-glucoside were decreased while physcion and emodin were increased. But physcion and emodin were decreased after $32 \mathrm{~h}$ which might be related to other chemical reactions occurring in the process. The reason for this needs to be studied in further work. As a result, processing could affect the concentrations of bioactive components.

In order to understand the effect of processing on P. multiflorum more clearly, principal component analysis (PCA) was employed for exploring the effects of processing on quality of P. multiflorum. The sum of PC1 and PC2 was higher than $85.33 \%$ of total variance, which could be sufficient to describe the variability. The score plot for these compounds generated from comparison of two PCs is illustrated in Figure 3. 13 samples of different processing times were classified into 4 groups. $P$. multiflorum with no processing and $4 \mathrm{~h}$ processing were clustered into one group, respectively. Samples that were processed 8 to $16 \mathrm{~h}$ were classified into one group and 20 to $32 \mathrm{~h}$ were clustered into another group. Based on this, the quality control of $P$. multiflorum becomes more comprehensive; this could be employed as a standard for the herbal medicines in the market.

\section{Conclusion}

In this study, a bioactivity-based UHPLC-Q-TOF-MS-FC method was developed and validated to successfully screen and identify lipase inhibitors from P. multiflorum. The active components were used in clarifying the effects of processing on the quality of $P$. multiflorum. The method could provide the total activity of the extract, the activity of the factions and individual components, and the contribution of the active components in the herbal medicines. Compared with conventional methods, the developed method was more rapid, effective, and comprehensive for the active components screening and identification of lipase inhibitors in TCMs. As a result, stilbenes and anthraquinones in $P$. multiflorum were screened to have the potential lipase inhibitory effect, which could be used as safe lipase inhibitors for the treatment of obesity. These results give scientific support for the clinical use and specification for processing in the market for P. multiflorum.

\section{Conflict of Interests}

The authors have declared that there is no conflict of interests regarding the publication of this paper.

\section{Acknowledgments}

This research was supported by National Natural Science Foundation of China (81374050), National Science and Technology Support Program Projects (2014BA105B01), Program for Innovative Research Team in Universities of Tianjin (TD12-5033), Tianjin Research Program of Application Foundation and Advanced Technology (12JCQNJC08800), and State Science \& Technology Commission of MOST of China (2014ZX09304307001).

\section{References}

[1] B. M. Balsiger, M. M. Murr, J. L. Poggio, and M. G. Sarr, "Bariatric surgery: surgery for weight control in patients with morbid obesity," Medical Clinics of North America, vol. 84, no. 2, pp. 477-489, 2000.

[2] G. A. Bray, "The underlying basis for obesity: relationship to cancer," Journal of Nutrition, vol. 132, no. 11, supplement, pp. 3451-3455, 2002.

[3] M. Hanefeld and G. Sachse, "The effects of orlistat on body weight and glycaemic control in overweight patients with type 2 diabetes: a randomized, placebo-controlled trial," Diabetes, Obesity and Metabolism, vol. 4, no. 6, pp. 415-423, 2002.

[4] T. D. Filippatos, C. S. Derdemezis, I. F. Gazi, E. S. Nakou, D. P. Mikhailidis, and M. S. Elisaf, "Orlistat-associated adverse effects 
and drug interactions: a critical review," Drug Safety, vol. 31, no. 1, pp. 53-65, 2008.

[5] S. Henness and C. M. Perry, "Orlistat: a review of its use in the management of obesity," Drugs, vol. 66, no. 12, pp. 1625-1656, 2012.

[6] J. H. Ahn, Q. Liu, C. Lee et al., "A new pancreatic lipase inhibitor from Broussonetia kanzinoki," Bioorganic \& Medicinal Chemistry Letters, vol. 22, no. 8, pp. 2760-2763, 2012.

[7] R. B. Birari and K. K. Bhutani, "Pancreatic lipase inhibitors from natural sources: unexplored potential," Drug Discovery Today, vol. 12, no. 19-20, pp. 879-889, 2007.

[8] A. L. de la Garza, F. I. Milagro, N. Boque, J. Campión, and J. A. Martínez, "Natural inhibitors of pancreatic lipase as new players in obesity treatment," Planta Medica, vol. 77, no. 8, pp. 773-785, 2011.

[9] E. M. Lee, S. S. Lee, B. Y. Chung et al., "Pancreatic lipase inhibition by C-glycosidic flavones isolated from Eremochloa ophiuroides," Molecules, vol. 15, no. 11, pp. 8251-8259, 2010.

[10] Commission of Chinese Pharmacopoeia, Pharmacopoeia of the People's Republic of China, vol. 1, China Medical Science Press, Beijing, China, 2010.

[11] J. B. Li and M. Lin, "Studies on chemical constituents of Polygonum multiflorun," Chinese Traditional and Herbal Drugs, vol. 24, no. 3, pp. 115-118, 1993.

[12] H. K. Kim, Y. H. Choi, J. S. Choi et al., "A new stilbene glucoside gallate from the roots of Polygonum multiflorum," Archives of Pharmacal Research, vol. 31, no. 10, pp. 1225-1229, 2008.

[13] L. X. Zhou, M. Lin, J. B. Li, and S. Z. Li, "Chemical studies on the ethyl acetate insoluble fraction of the roots of Polygonum mutifloum Thunb," Acta Pharmacologica Sinica, vol. 29, no. 2, pp. 107-110, 1994.

[14] C.-C. Wong, H.-B. Li, K.-W. Cheng, and F. Chen, "A systematic survey of antioxidant activity of 30 Chinese medicinal plants using the ferric reducing antioxidant power assay," Food Chemistry, vol. 97, no. 4, pp. 705-711, 2006.

[15] A. Luximon-Ramma, T. Bahorun, M. A. Soobrattee, and O. I. Aruoma, "Antioxidant activities of phenolic, proanthocyanidin, and flavonoid components in extracts of Cassia fistula," Journal of Agricultural and Food Chemistry, vol. 50, no. 18, pp. 50425047, 2002.

[16] T. K. Yim, W. K. Wu, D. H. F. Mak, and K. M. Ko, "Myocardial protective effect of an anthraquinone-containing extract of Polygonum multiflorum ex vivo," Planta Medica, vol. 64, no. 7, pp. 607-611, 1998.

[17] R. Qin, X. B. Li, G. Li et al., "Protection by tetrahydroxystilbene glucoside against neurotoxicity induced by $\mathrm{MPP}^{+}$: the involvement of PI3K/Akt pathway activation," Toxicology Letters, vol. 202, no. 1, pp. 1-7, 2011.

[18] T. Wang, Y. J. Yang, P. F. Wu et al., “Tetrahydroxystilbene glucoside, a plant-derived cognitive enhancer, promotes hippocampal synaptic plasticity," European Journal of Pharmacology, vol. 650, no. 1, pp. 206-214, 2011.

[19] X. Jia, J.-Z. Chen, Z.-F. Yang et al., "Neuroprotective effect of tetrahydroxystilbene glucoside on the rat model of Parkinson's disease," Chinese Journal of New Drugs, vol. 17, no. 9, pp. 748752, 2008.

[20] W. Fang, Y. W. Qin, L. Y. Wang et al., “The protecting effect of PMTG on the atherosclerotic lesion formation," Chinese Journal of Drug Application and Monitoring, vol. 1, pp. 48-51, 2005.

[21] W. G. Wang, Y. R. He, P. Lin et al., "In vitro effects of active components of Polygonum Multiflorum Radix on enzymes involved in the lipid metabolism," Journal of Ethnopharmacology, vol. 153, no. 3, pp. 763-770, 2014.

[22] J. M. Wang, R. H. Zhao, W. G. Wang, X. J. Mao, and J. Yu, "Lipid regulation effects of Polygoni Multiflori Radix, its processed products and its major substances on steatosis human liver cell line L02," Journal of Ethnopharmacology, vol. 139, no. 1, pp. 287293, 2012.

[23] B. M. Hybertson, B. Gao, S. K. Bose, and J. M. McCord, "Oxidative stress in health and disease: the therapeutic potential of Nrf2 activation," Molecular Aspects of Medicine, vol. 32, no. 4-6, pp. 234-246, 2011.

[24] J.-L. Zhou, G.-Z. Xin, Z.-Q. Shi et al., "Characterization and identification of steroidal alkaloids in Fritillaria species using liquid chromatography coupled with electrospray ionization quadrupole time-of-flight tandem mass spectrometry," Journal of Chromatography A, vol. 1217, no. 45, pp. 7109-7122, 2010.

[25] J. Zeng, X. Zhang, Z. Guo et al., "Separation and identification of flavonoids from complex samples using off-line twodimensional liquid chromatography tandem mass spectrometry," Journal of Chromatography A, vol. 1220, pp. 50-56, 2012.

[26] X. L. Cheng, F. Wei, X. Y. Xiao et al., "Identification of five gelatins by ultra performance liquid chromatography/time-offlight mass spectrometry (UPLC/Q-TOF-MS) using principal component analysis," Journal of Pharmaceutical and Biomedical Analysis, vol. 62, pp. 191-195, 2012.

[27] J. Zhang, Y. Jin, J. Dong et al., "Systematic screening and characterization of tertiary and quaternary alkaloids from corydalis yanhusuo W.T. Wang using ultra-performance liquid chromatography-quadrupole-time-of-flight mass spectrometry," Talanta, vol. 78, no. 2, pp. 513-522, 2009.

[28] Y. Tao, Y. F. Zhang, Y. Wang, and Y. Y. Cheng, "Hollow fiber based affinity selection combined with high performance liquid chromatography-mass spectroscopy for rapid screening lipase inhibitors from lotus leaf," Analytica Chimica Acta, vol. 785, pp. 75-81, 2013.

[29] K. Xiao, L.-J. Xuan, Y.-M. Xu, and D.-L. Bai, "Novel stilbene glycosides from polygonum multiflorum," Acta Botanica Sinica, vol. 44, no. 12, pp. 1491-1494, 2002.

[30] X. Qiu, J. Zhang, Z. Huang, D. Zhu, and W. Xu, "Profiling of phenolic constituents in Polygonum multiflorum Thunb. by combination of ultra-high-pressure liquid chromatography with linear ion trap-Orbitrap mass spectrometry," Journal of Chromatography A, vol. 1292, pp. 121-131, 2013.

[31] Z. W. Zhu, J. Li, X. M. Gao et al., "Simultaneous determination of stilbenes, phenolic acids, flavonoids and anthraquinones in Radix polygoni multiflori by LC-MS/MS," Journal of Pharmaceutical and Biomedical Analysis, vol. 62, pp. 162-166, 2012.

[32] M. Ye, J. Han, H. B. Chen, J. H. Zheng, and D. A. Guo, "Analysis of phenolic compounds in rhubarbs using liquid chromatography coupled with electrospray ionization mass spectrometry," Journal of the American Society for Mass Spectrometry, vol. 18, no. 1, pp. 82-91, 2007. 


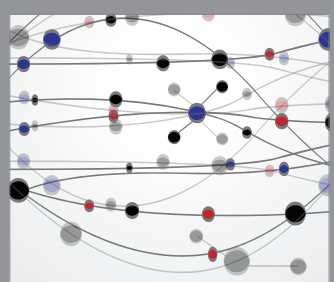

The Scientific World Journal
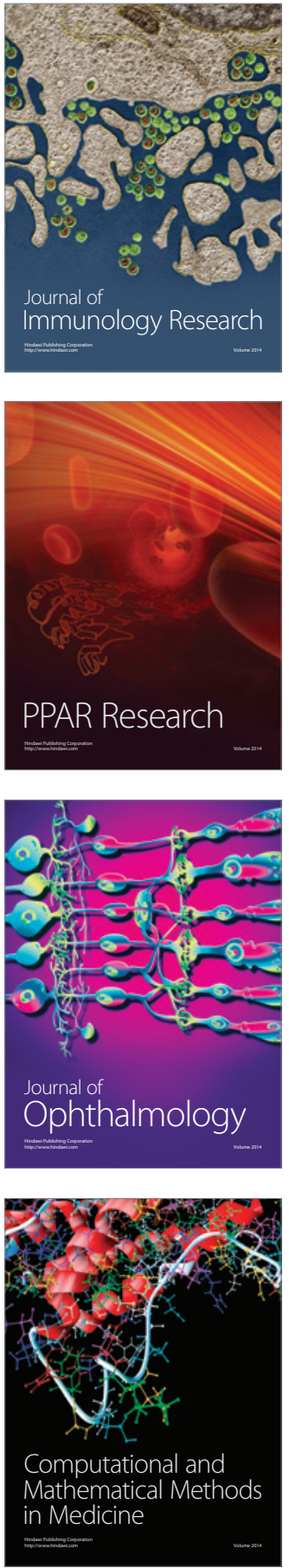

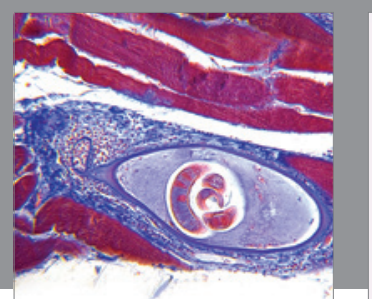

Gastroenterology Research and Practice

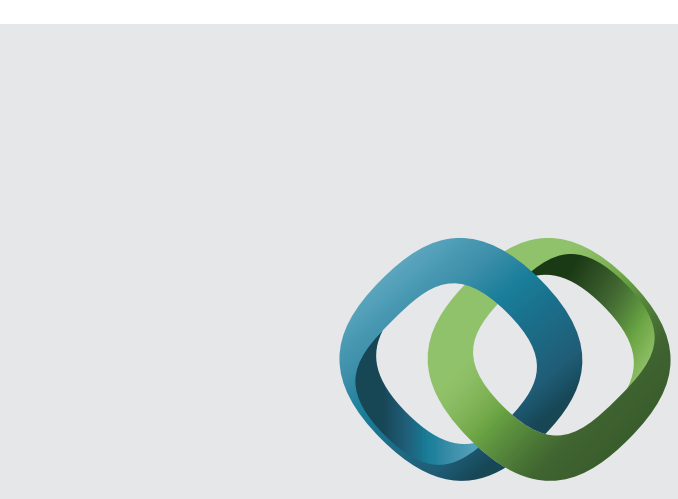

\section{Hindawi}

Submit your manuscripts at

http://www.hindawi.com
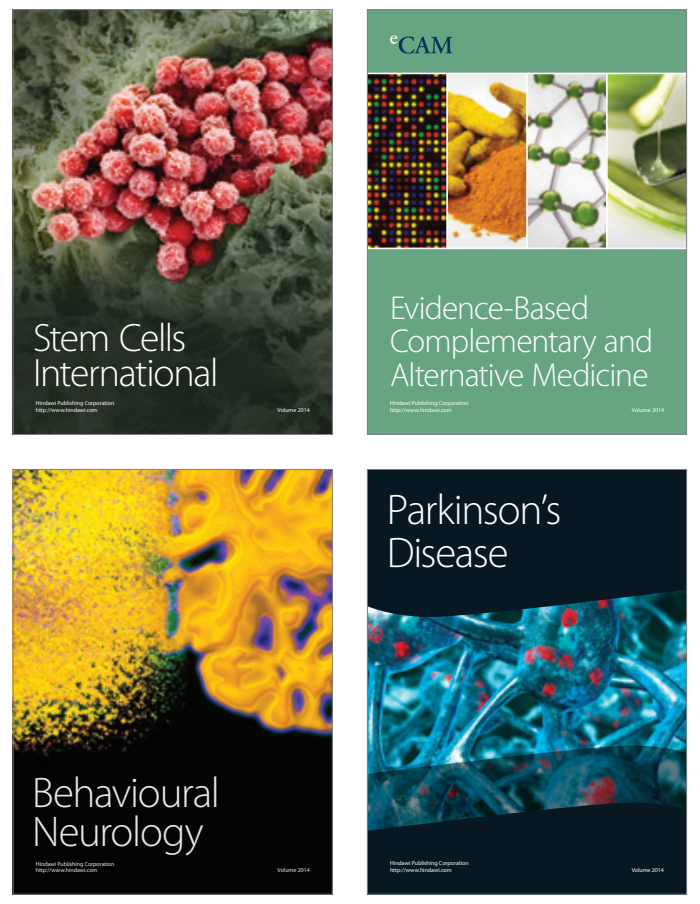
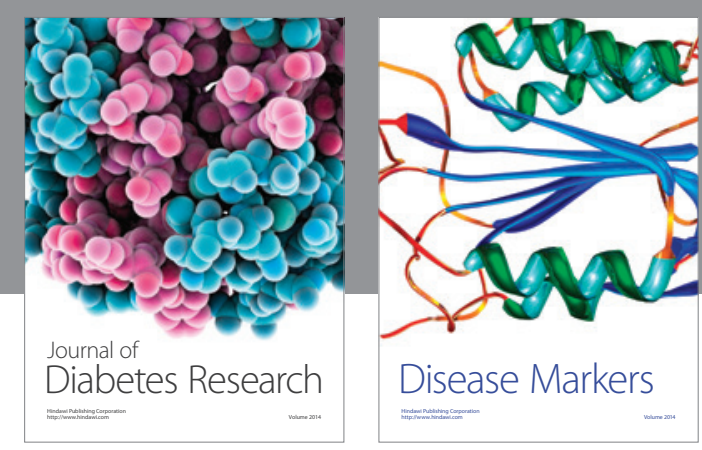

Disease Markers
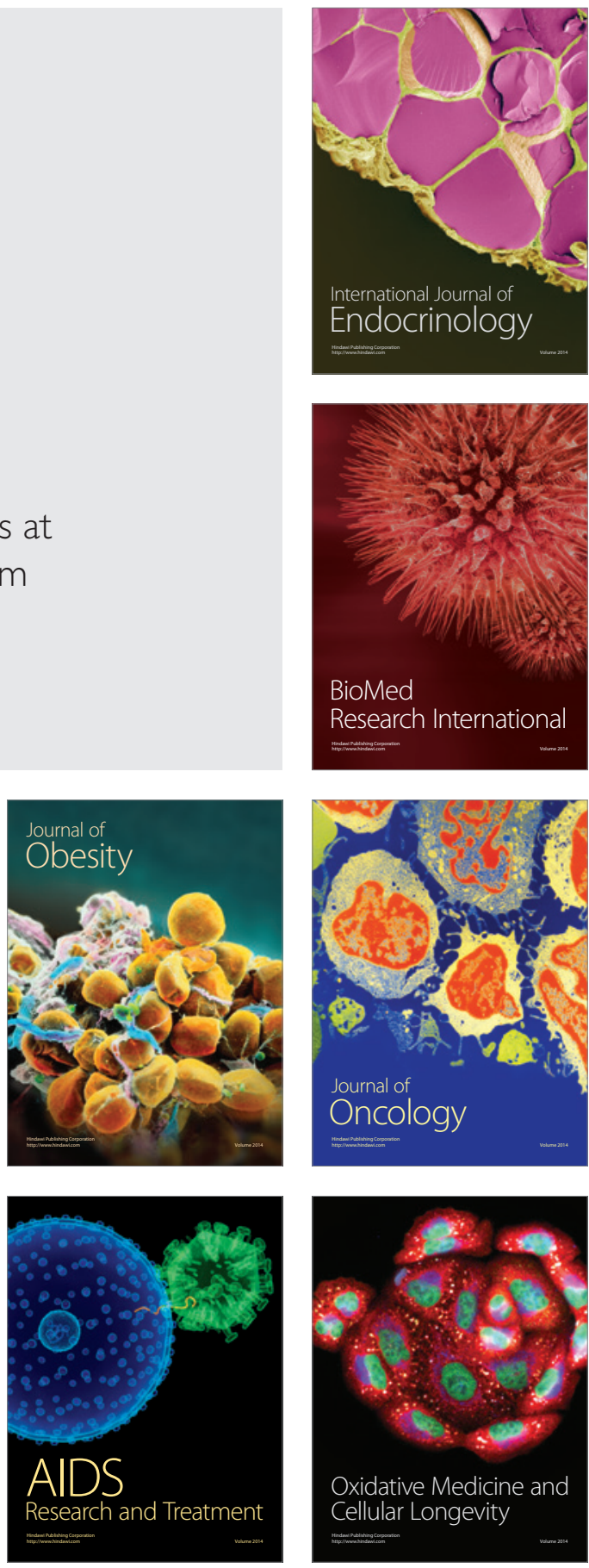